\title{
Evaluation of a height/plasma creatinine formula in the measurement of glomerular filtration rate
}

\author{
M C MORRIS, C W ALLANBY, P TOSELAND, G B HAYCOCK, AND C CHANTLER \\ Evelina Children's Department and the Department of Clinical Chemistry, Guy's Hospital, London
}

SUMmARY The clinical usefulness of the quantity height $(\mathrm{cm}) /$ plasma creatinine $\left(\mathrm{Ht} / \mathrm{P}_{\mathrm{cr}}\right)$ as a predictor of glomerular filtration rate (GFR) was investigated in 163 children with varying levels of renal function. Plasma creatinine levels $(\mu \mathrm{mol} / \mathrm{l})$ were measured by an automated reaction rate method. The results indicate that in rather more than half the children studied, an estimate of GFR adequate for ordinary clinical purposes will be obtained from $\mathrm{Ht} / \mathrm{P}_{\mathrm{cr}}$, or from the derived formula GFR $\left(\mathrm{ml} / \mathrm{min}\right.$ per $\left.1.73 \mathrm{~m}^{2}\right)=40 \mathrm{Ht} / \mathrm{P}_{\mathrm{cr}}$. The accuracy of the prediction is greatest in children with reduced function (GFR $<80 \mathrm{ml} / \mathrm{min}$ per $1.73 \mathrm{~m}^{2}$ ) and in this group of patients a change of GFR of $19 \mathrm{ml} / \mathrm{min}$ per $1.73 \mathrm{~m}^{2}$ or more is reliably detected by this method. We conclude that $\mathrm{Ht} / \mathrm{P}_{\mathrm{cr}}$ is a clinically useful aid to the estimation of renal function, reducing the need for formal GFR measurements by at least half.

The plasma concentration of creatinine $\left(P_{c r}\right)$ is known to vary inversely with glomerular filtration rate (GFR), and is widely used as a simple index of renal function and for detecting changes in GFR with time. In healthy children aged over 2 years GFR remains constant after correction for body surface area, while plasma creatinine rises with age; this is due to the changing relationship between body mass, and hence creatinine production, and surface area, and hence GFR. Tables of normal values for $\mathbf{P}_{\mathrm{cr}}$ in children of different ages have been published ${ }^{1-4}$ and are available for reference. However, just as GFR is conventionally normalised by standardising for body surface area, it would be a great convenience if some means could be found for correcting $\mathbf{P}_{\mathrm{c}}$, for variations in body size. Dimensional analysis of the relationship between creatinine production and excretion, on the one hand, and increasing body size, on the other, leads to the prediction that the quantity height divided by $\mathrm{P}_{\mathrm{cr}}$ $\left(\mathrm{Ht} / \mathrm{P}_{\mathrm{cr}}\right)$ is correlated with corrected GFR; $;^{5}$ two experimental studies ${ }^{56}$ have confirmed this prediction. The present study was designed to define more precisely the clinical value of a formula based on the above relationship, and to determine its sensitivity and confidence limits. In addition, the accuracy and reproducibility of an automated reaction rate method for laboratory estimation of $P_{c r}$ was investigated.

\section{Patients studied}

Children aged between 2 and 14 years who were investigated for possible renal disease at Guy's Hospital between 1976 and 1979 were studied. Patients with gross oedema, marked reduction in muscle mass, or with rapidly changing renal function were excluded. The patients were divided into two groups, one of which was used to derive the relationship between GFR and $\mathrm{Ht} / \mathrm{P}_{\mathrm{cr}}(94$ children) while the other (69 children) was used to test the validity and usefulness of the derived relationship.

\section{Methods}

Height was measured with a Harpenden stadiometer, and body surface area was calculated from height and weight according to the formula of Haycock et al. ${ }^{7}$ GFR was measured by single exponential analysis of the plasma disappearance curve of ${ }^{51} \mathrm{Cr}$ EDTA as described by Chantler and Barratt. ${ }^{8} \mathrm{P}_{\mathrm{cr}}$ was estimated by a method which measures the rate of generation of colour during incubation of the sample with alkaline picrate; a modified LKB 2086 automatic analyser was used. ${ }^{9}$ The plasma sample was obtained in all cases within 3 days of the GFR measurement, and generally at the same time. Technically unsatisfactory GFR measurements were excluded. If the ratio calculated volume of distribu- 
tion of EDTA:body weight came outside the limits $0 \cdot 2-0.4$ the result was also discarded. This exclusion was based on analysis of 176 studies in which the ratio had a skewed normal distribution about the value $30 \%$, with a right hand tail due to patients with oedema. Sixteen per cent of all GFRs were thus excluded.

Reproducibility of the LKB $P_{c_{r}}$ method was tested by repeated estimation, 13-15 times, of a single sample from each of 3 patients. The day-to-day variation of $\mathbf{P}_{\mathrm{cr}}$ in individuals with presumably stable renal function was tested by collecting 10 venous blood samples from each of 19 normal young adults during a 30-day period, samples being drawn at 0900 hours after an overnight fast.

The accuracy with which a measured change in GFR can be predicted from a change in $\mathrm{Ht} / \mathrm{P}_{\mathrm{cr}}$ was examined by analysing the correlation between the change in predicted GFR and the change in measured GFR in those patients who had two or more GFRs below $90 \mathrm{ml} / \mathrm{min}$ per $1.73 \mathrm{~m}^{2}$. There were 84 observations from 32 patients.

\section{Results}

The pooled coefficient of variation of the laboratory method, derived by repeated estimates of the same samples, was $2.6 \%$. That obtained by estimating repeated samples from the same patients was $4.4 \%$.

$\mathrm{Ht} / \mathrm{P}_{\mathrm{cr}}$ was strongly correlated with GFR (Fig. 1). A value of $\mathrm{Ht} / \mathrm{P}_{\mathrm{cr}}$ less than 1.5 corresponded to a GFR less than $80 \mathrm{ml} / \mathrm{min}$ per $1.73 \mathrm{~m}^{2}$, while a value greater than $2 \cdot 1$ predicted a GFR greater than 80 .

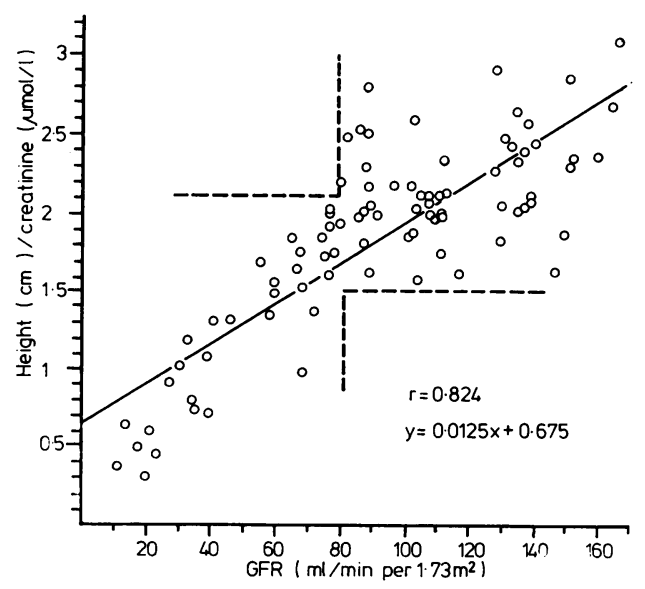

Fig. 1 Height/plasma creatinine plotted against GFR. The broken lines show that no subject with height/ creatinine quotients $>2.1$ or $<1.5$ had a GFR below or above $90 \mathrm{ml} / \mathrm{min}$ per $1.73 \mathrm{~m}^{2}$.
Thirty children came into the former category and 20 into the latter, while $44 \mathrm{had} \mathrm{Ht} / \mathrm{P}_{\mathrm{cr}}$ between 1.5 and $2 \cdot 1$. Inspection of Fig. 1 shows that the scatter of points is much wider at values of GFR above 90 than below, and an even better fit is obtained by analysing values obtained from children with GFR $<90$ only (Fig. 2). In this group the relationship between GFR and $\mathrm{Ht} / \mathrm{P}_{\mathrm{cr}}$ is contained in the equation:

GFR $\left(\mathrm{ml} / \mathrm{min}\right.$ per $\left.1.73 \mathrm{~m}^{2}\right)=40 \times$ height $(\mathrm{cm}) / \mathrm{P}_{\mathrm{cr}}$ $(\mu \mathrm{mol} / \mathrm{l})$.

When applied to a different group of children in the same range of function, this formula gave a reliable prediction of GFR (Fig. 3).

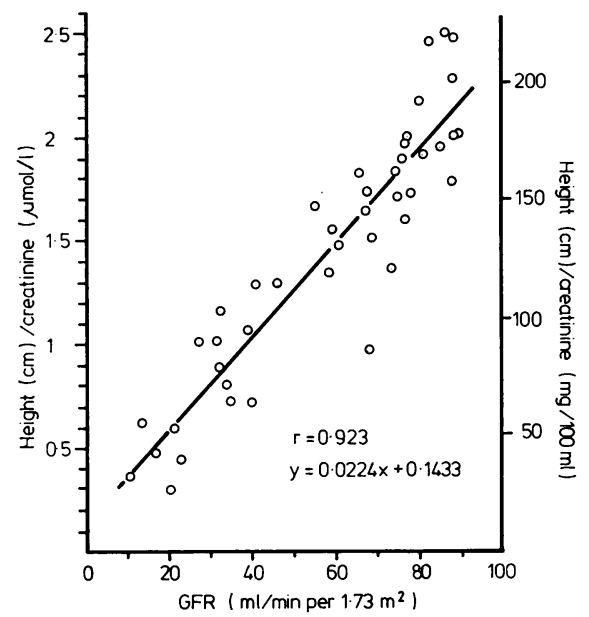

Fig. 2 Height/plasma creatinine plotted against GFR in patients with GFR $<90 \mathrm{ml} / \mathrm{min}$ per $1.73 \mathrm{~m}^{2}$.

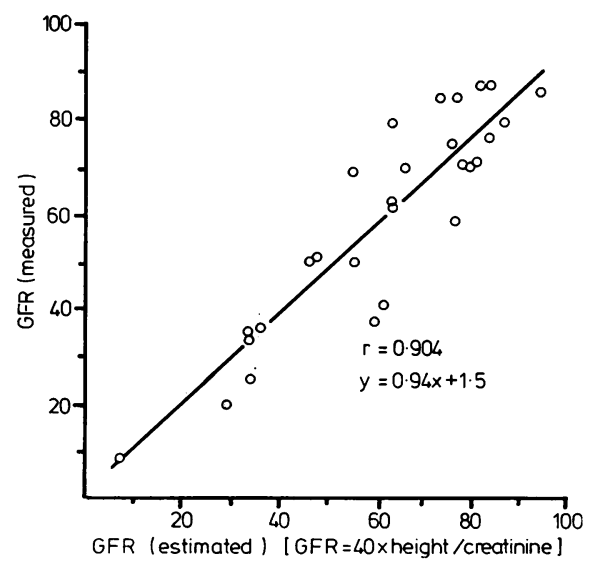

Fig. 3 Correlation between measured and estimated GFR in patients with $G F R<90 \mathrm{ml} / \mathrm{min}$ per $1.73 \mathrm{~m}^{2}$. 


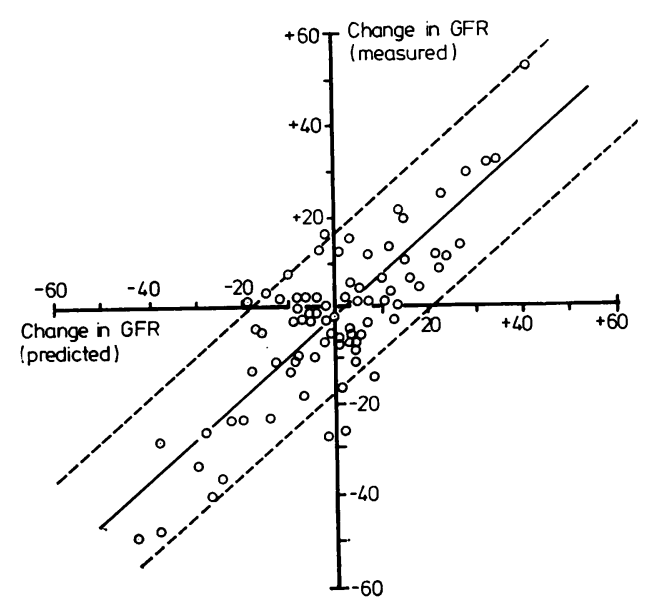

Fig. 4 Relationship between sequential changes in measured and predicted GFR.

$\mathrm{Ht} / \mathrm{P}_{\mathrm{cr}}>2 \cdot 1$ correctly predicted GFR $>80 \mathrm{ml} /$ $\min$ per $1.73 \mathrm{~m}^{2}$ in 23 of 24 subjects; $\mathrm{Ht} / \mathrm{P}_{\mathrm{cr}}<1.5$ correctly predicted GFR $<80 \mathrm{ml} / \mathrm{min}$ per $1.73 \mathrm{~m}^{2}$ in 12 of 13 .

The correlation between change in measured GFR and change in GFR predicted from $40 \mathrm{Ht} / \mathrm{P}_{\mathrm{cr}}$ is shown in Fig. 4. The correlation coefficient was 0.828 and the $95 \%$ confidence limit for the prediction was $\pm 19 \mathrm{ml} / \mathrm{min}$ per $1.73 \mathrm{~m}^{2}$.

\section{Discussion}

Two difficulties have in the past complicated the use of $P_{c r}$ as a direct index of GFR in children. The first of these is the fact that, in health, the normal $P_{c r}$ in small children is so low that the unmodified alkaline picrate reaction is seriously interfered with by 'non-creatinine chromogens' in plasma. The Technicon Auto Analyzer ${ }^{10}$ version of this method can be modified to increase sensitivity into the paediatric range $^{6}$ but it is still unsatisfactory at very low concentrations. Various 'true' creatinine methods rely on removal of interfering substances by means of Fuller's earth or resin absorption, ${ }^{5}$ but are too time-consuming and tedious to be practical in routine use. The method used in this study is highly reproducible in the laboratory, and measures creatinine with great consistency within the same subject over a period of time. Extensive experience with the method in a large children's renal service has confirmed the impression given by the data presented in this paper-that is, it is a reliable and satisfactory technique that can be relied upon to reflect GFR sufficiently accurately for most clinical purposes.
The second difficulty lies in the fact that the mean and normal range of values for $\mathbf{P}_{\mathrm{cr}}$ is age and sex dependent, ${ }^{4}$ so that either a whole set of normal values must be memorised or some means of standardising must be found. The $\mathrm{Ht} / \mathrm{P}_{\mathrm{cr}}$ quotient has been well documented as a means of doing this ${ }^{56}$ and the data reported here add further support to the value of the formula, as well as defining more accurately than before its confidence limits. The children on whom this study was based were typical of the range of subjects referred to a paediatric renal clinic and therefore may be taken as representative of the type of patients on whom such formulae are most likely to be used. If $\mathbf{P}_{\mathrm{cr}}$ is used as a means of screening-that is, separating children with normal GFR from those which abnormal GFR - then in rather more than half (50/94) this will be achieved $\left(\mathrm{Ht} / \mathrm{P}_{\mathrm{cr}}<1.5\right.$ or $\left.>2.1\right)$. In the minority - that is, those with $\mathrm{Ht} / \mathrm{P}_{\mathrm{cr}} 1 \cdot 5-2 \cdot 1$-clearly this was not achieved and it would seem appropriate to submit them to a more accurate GFR measurement. Since $\mathrm{Ht} / \mathbf{P}_{\mathrm{cr}}>2 \cdot 1$ indicates normal function, formal GFR measurement would add little of value and may safely be omitted from the assessment of renal function in children who equal or exceed this value. At the other end of the scale, when $\mathrm{Ht} / \mathrm{P}_{\mathrm{cr}}$ is less than 1.5 which is equivalent to saying that GFR is less than $80 \mathrm{ml} / \mathrm{min}$ per $1.73 \mathrm{~m}^{2}$, the prediction of GFR from $40 \mathrm{Ht} / \mathrm{P}_{\mathrm{cr}}$ is probably good enough for normal clinical purposes. Thus, the net effect of interpreting $P_{c r}$ in this way is to reduce the number of clearance or other GFR procedures by rather more than half, a very substantial saving in time and resources. We feel that those children with $\mathrm{Ht} / \mathrm{P}_{\mathrm{cr}}$ values between 1.5 and 2.1 warrant GFR measurement by a more precise method, since it is important to establish whether or not renal function is within the normal range.

If $P_{\mathrm{cr}}$ is used as a means of following GFR in a patient with known renal disease, our data show that a change in predicted GFR of $19 \mathrm{ml} / \mathrm{min}$ per $1.73 \mathrm{~m}^{2}$ or greater indicates with $95 \%$ confidence that a real change in renal function has occurred. We conclude that the quantity $\mathrm{Ht} / \mathbf{P}_{\mathrm{cr}}$, and the formula $40 \mathrm{Ht} / \mathbf{P}_{\mathrm{cr}}$ derived from it, are of considerable value in the assessment of renal function in children, provided that the limitations here defined are known and respected. This will in part depend on the laboratory method used for creatinine determination. We have found the reaction rate method to be highly satisfactory in this respect. Extrapolating from the pooled coefficient of variation for multiple samples suggests that a change of about $9 \%$ in the measured $\mathbf{P}_{\mathrm{cr}}$, in a patient whose height has not increased in the interval, can be interpreted at the $95 \%$ confidence level as meaning that a greater 
change in GFR has taken place than can be accounted for by normal day-to-day variation.

\section{References}

1 Josephson B, Fürst P, Järnmark O. Age variations in the concentration of non-protein nitrogen, creatinine, and urea in blood of infants and children. Acta Paediatr Scand [Suppl] 1962; Supplement 135, 111-20.

2 Kuhlbäck B, Pasternack A, Launiala K, Stenberg M. Serum creatinine and creatinine in children and adolescents. Scand J Clin Lab Invest 1968; 22: 37-40.

3 Donckerwolcke R A M G, Sander P C, van Stekelenburg G J, Stoop J W, Tiddens H A W M. Serum creatinine values in healthy children. Acta Paediatr Scand 1970; 59: $399-402$.

4 Schwartz G J, Haycock G B, Spitzer A. Plasma creatinine and urea concentration in children: normal values for age and sex. $J$ Pediatr 1976; 88: 828-30.

5 Counahan R, Chantler C, Ghazali S, Kirkwood B, Rose F, Barratt T M. Estimation of glomerular filtration rate from plasma creatinine concentration in children. Arch Dis Child 1976; 51 : 875-8.

- Schwartz G J, Haycock G B, Edelmann C M, Jr, Spitzer A. A simple estimate of glomerular filtration rate in children derived from body length and plasma creatinine. Pediatrics 1976; 58: 259-63.

7 Haycock G B, Schwartz G J, Wisotsky D H. Geometric method for measuring body surface area: a height-weight formula validated in infants, children, and adults. $J$ Pediatr 1978; 93: 62-6.

8 Chantler C, Barratt T M. Estimation of glomerular filtration rate from plasma clearance of 51-chromium edetic acid. Arch Dis Child 1972; 47: 613-7.

9 Cook J G H. Creatinine assay in the presence of protein. Clin Chim Acta 1971; 32: 485-6.

10 Technicon method N-IIa: estimation of creatinine. In: Auto analyzer $N$ methodology. New York: Technicon Instruments Corpn, 1963.

Correspondence to Dr G B Haycock, Department of Paediatrics, Guy's Hospital, St Thomas Street, London SE1 9RT.

Received 18 December 1981

\section{Commentary}

\section{MARTIN BARRATT}

Department of Nephrology, Institute of Child Health, London

Morris et al. ${ }^{1}$ and Davies et al. ${ }^{2}$ present almost identical data, but come to seemingly opposed conclusions about the value of plasma creatinine $\left(P_{c r}\right)$ as an estimate of glomerular filtration rate (GFR) in children. The underlying principles need to be considered.

There is no single test that encompasses all aspects of renal function, but the glomerular filtration rate commands the greatest attention for it determines the filtered load presented to the renal tubules and thus the flexibility of the renal response to homeostatic requirements and, in the long run, decline in GFR is the principal functional abnormality underlying chronic renal failure.

The GFR has somehow to be viewed in relation to the child's size, and convention decrees that body surface area (SA) is the most appropriate reference standard as GFR/SA is constant over age 2 years, although McCance and Widdowson ${ }^{3}$ made a strong case for total body water, this being the domain over which the kidney exercises its homeostatic function. Tanner ${ }^{4}$ is required reading on the problem of per-weight and per-surface area standards, and describes situations 'where investigators had drawn positive conclusions not justified by their data, had been confused by a seemingly uninterpretable phenomenon in their data, had proposed a less effective and more biased normal standard in preference to a more effective and less biased one, had reduced a correlation between two physiological functions from a very high to a median value, and had invented a new clinical syndrome.' It does not inspire confidence that the best method of estimating SA in young children views them as an assembly of cylinders and spheres. ${ }^{5}$

The clearance of inulin remains the definitive estimate of GFR but is technically demanding; creatinine clearance exceeds GFR due to tubular secretion and is in any case a nuisance as timed urine collections are required. The clearance of 51-chromium edetic acid ${ }^{(51} \mathrm{Cr}$-EDTA) is virtually equal to that of inulin, and a reasonable and convenient estimate of GFR can be obtained from the rate of fall of plasma concentration after intravenous injection. However, analysis of the plasma disappearance on a single compartmental model leads to an overestimate of GFR owing to the fact that the extracellular fluid is not an ideal 'well-stirred pool', and there is delay in equilibration, necessitating what is known in the trade as the 'Chantler fudge factor'. ${ }^{6}$ It is therefore somewhat hazardous to assess other methods of estimating GFR by comparing them with the plasma clearance of ${ }^{51} \mathrm{Cr}$-EDTA.

Transformation of the clearance equation thus: $\mathbf{P}_{\mathrm{cr}}=\mathbf{U}_{\mathrm{c}} \mathrm{V} / \mathrm{C}_{\mathrm{c}}$

indicates that the plasma creatinine concentration $\left(P_{c r}\right)$ is directly proportional to creatinine excretion (UcV, and hence production) and inversely proportional to creatinine clearance $\left(C_{c}\right.$, and hence GFR), and thus GFR should be predictable from $P_{c r}$ if $\mathrm{UcV}$ is defined. However, creatinine production bears a complicated relationship to height $(\mathrm{Ht})$ and weight $(\mathrm{Wt}) .^{7}$ Theoretical arguments ${ }^{8}$ and empirical analysis ${ }^{9}$ indicated that GFR/SA correlated best 